\title{
ECLAMPSIA : AN OBSTETRIC DISASTER
}

Pradhan $\mathbf{P}$

\section{ABSTRACT}

Eclampsia has been graded as fatal and dreadful disease even before Christ and is the important cause of maternal and perinatal mortality in developed and developing countries. Severe morbidity associated with eclampsia include placental abruptio, cerebral haemorrhage, cortical blindness, renal failure, disseminated intravascular coagulopathy, pulmonary oedema, psychosis and growth retardation and preterm or both. Present management of eclampsia aims to stop the convulsions, its recurrences, control of blood pressure and correct fluid and electrolyte balance and delivery of the baby. There have been great controversies about the best anticonvulsants to use. The randomised trials comparing magnesium sulphate with diazepam or phenytoin showed greater efficacy of magnesium sulphate in the control and prevention of recurrence of fits. Perinatal mortality is also better with magnesium sulphate. Intramuscular injection is painful and local abscess formation at the site of injection is possible. Control of dose is better with intravenous route therefore preferred. Magnesium sulphate should be continued for $\mathbf{2 4}$ hours after the delivery or after the last fit. Antihypertensive drug therapy is now a routine practice in the management of pre-eclampsia and eclampsia. Methyl dopa, Lobetelol, Nefedipine are well tried in pregnancy and safe in pregnancy. However, hydralazine intravenous is good for quick and smooth control of blood pressure. Termination of pregnancy has been an important part of the management of eclampsia. Studies have shown that maternal outcomes seems better with caesarean delivery compared to vaginal delivery. The caesarean section rate is high at 26.3-80.4\% in different studies. Recently maternal mortality and morbidity has been greatly improved even in developing countries by better control of fits by magnesium sulphate and caring them in intensive care unit.

\section{Key Words: Eclampsia, Anticonvulsants, Antihypertensives, Delivery.}

\section{INTRODUCTION}

Eclampsia is defined as the occurrence of one or more convulsions in association with the syndrome of pre-eclampsia. Pre-eclampsia is a multi system disorder associated with hypertension and proteinuria and is a fairly common complication of pregnancy at around $10 \% .^{1}$ The incidence of eclampsia is reducing and it complicates 1 in 2000 deliveries in developed countries while in developing countries estimates vary widely from 1 in 100 to 1 in 700 deliveries..$^{2-4}$ The word eclampsia was first described in 1691 as a Greek word 'Ekampecin' mean 'Flash-out' because of visual phenomenon accompanying convulsions. ${ }^{5}$ Despite the rarity of this severe disease, it is still a major cause of maternal mortality and is a factor in $2-10 \%$ of direct maternal death in developed countries. ${ }^{6,7}$ In the developing countries, where maternal mortality rate is 100-200 times higher than Europe and North America, it has been estimated that $10-22 \%$ of all maternal deaths are attributed to eclampsia. ${ }^{8,9,10}$ Despite the higher prevalence of eclampsia in developing countries and the wealth

Address for correspondence : Prof. P. Pradhan

Nepal Medical College and Teaching Hospital

Atterkhel, Jorpati

P.O. Box: 13344, Kathmandu, Nepal.

Email: nmc@nmcth.edu 
of experience gained in its management, maternal mortality rates remain high. This may be partly due to the fact that preeclampsia is a multi system disease and the extent of involvement of the various organs is unpredictable. Treatment of pre-eclampsia and eclampsia is also empirical because the pathology of this condition remains unknown. Maternal mortality in eclampsia results from combination of several factors. Most important issue is whether the patient has recurrence of fits, reaches the hospital in reversible stage or her condition is already in bad shape. Mortality is very high $(37.7-46 \%)$ in patients who are deeply comatosed on admission. ${ }^{11,12}$ Lack of prenatal care is associated with increased risk of comlicated eclampsia and maternal mortality of 33.3\% reported in complicated eclampisa and none in uncomplicated eclampsia. ${ }^{12-14}$ Ozumbic BC et al ${ }^{15}$ reported the incidence of eclampsia among unbooked cases was 4.3/1000 birth compared to $1.1 / 1000$ birth among booked cases. In Nepal $13 \%$ of ostetrics population have antenatal care provided by doctors and $11 \%$ by midwives and nurses. ${ }^{9}$ On the other hand Douglas and Redman ${ }^{2}$ reported that eclampsia was seen despite antenatal care and within a week of women last visit to a midwife or doctor. Probably routine screening methods during antenatal check up may not detect all potential eclamptic women and eclampsia is often unpredictable and therefore not completely preventable. The problem is not limited to that of maternal mortality. Severe morbidity associated with eclampsia include placental abruption, cerebral haemorrhage, cortical blindness, renal failure, disseminated intravascular coagulopathy, pulmonary oedema and psychosis are very important. ${ }^{7}$ In Sweden during 1976-80 nearly 15\% of affected women had serious maternal complication in addition to eclamptic convulsion ${ }^{16}$. Douglas and Redman 2 demonstrated that $35 \%$ of the eclamptic patients had at least one or other complication whereas the collaborative eclampsia trial ${ }^{17}$ found the incidence of morbidity ranging from $12.4 \%$ to $25.3 \%$. Eclampsia is also a major cause of perinatal death worldwide. The collaborative eclampsia trial found the incidence of perinatal mortality range from 177-307/1000 total birth. ${ }^{17}$ Douglas and Redman ${ }^{2}$ from UK found a rate of 56/1000 total birth. In Nepal, the rate of 200-300/1000 birth reported $1^{8,19}$ late arrival of patients after the onset of fits results in intrauterine hypoxia and intrauterine death. The perinatal mortality is more related to gestational age at delivery than to the severity of disease. A further improvement in neonatal survival for infants born to eclamptic mothers will depend on therapy that will allow prolongation of pregnancy or on future advances in neonatal care. The great risk for the fetus is when eclamptic fits with their attendant period of acute maternal and therefore fetal anoxia occurs before delivery and the fetus is already compromised by placental insufficiency. ${ }^{20,21}$ Detecting pre-eclampsia and implementing treatment earlier might have been more effective. Treatment should be simple, avoiding large doses of drugs such as diazepam, which adversely affect the baby. ${ }^{19}$ Because of the perinatal problems resulting from anoxia more liberal recourse to caesarean section should be considered especially when there is evidence of impaired placental function and preterm delivery is required. ${ }^{1}$ Effectiveness of available beonatal care also determines the perinatal outcome.

\section{AETIOLOGY}

Genetic influence has long been regarded as aetiologically important in pre-eclampsia and eclampsia. ${ }^{22} \mathrm{~A}$ family history of pre-eclampsia and eclampsia is associated with 4 fold increase in the relative risk of severe pre-eclampsia in primigravida women. Inheritance was followed both through sons and daughters. The prevalence of pre-eclampsia and eclampsia in daughter was significantly higher $23 \%$ than that in daughters-in-laws $10 \%$ and appears to involve a genetically determined susceptibility possibly bases on single gene inheritance. ${ }^{23}$

\section{TREATMENT OF ECLAMPSIA}

Eclampsia remains one of the leading causes of maternal and perinatal mortality in many parts of the world. ${ }^{17,24,25}$ Present management of eclampsia aims to stop the convulsions and prevent recurrence, control of blood pressure, correct fluid and electrolyte imbalance and deliver the patient promptly. Standard practice is to use anti-convulsants to control fit immediately and prevent further seizures but the choice of an ideal anticonvulsant is controversial. Currently the most widely used anticonvulsants are diazepam, phenytoin and magnesium sulphate. ${ }^{26,27}$ Excellent reports have been reported from all these anticonvulsant drugs with respect to maternal and perinatal mortality. In UK and many other countries diazepam and phenytoin are favoured ${ }^{28,29}$ whereas magnesium sulphate is the drug of choice in USA.

In UK diazepam has been popular since 1970 and most clinicians agree that diazepam should be used for immediate control of convulsions rapidly. Diazepam is to be given according to the regime described by Lean and co-workers. ${ }^{29}$ A loading dose of $10 \mathrm{mg}$ intravenously over 2 minutes by an intravenous infusion of $40 \mathrm{mg}$ diazepam in $500 \mathrm{ml}$ of normal saline for 24 hour. The rate of infusionis titrated against the level of consciousness with the aim of overcoming restlessness and keeping the women sedated but rousable easily. During the next 24 hour, an infusion of $20 \mathrm{mg}$ of diazepam is $500 \mathrm{ml}$ normal saline is to be given and slowly reduced. Lean et al demonstrated a mortality rate of only $3.3 \%$ in a population of eclamptic patients who are moribound at the time of admission and were treated with diazepam and the hypertensive agent 
hydralazine. ${ }^{29}$ Diazepam is an inexpensive, readily available, easily administered and therefore suitable for use by staffs in outlying clinic and hospital before the eclamptic women can be transferred to the referral hospital. Concern over the respiratory and cortical depressant effects of large doses of diazepam on both fetus and mother have been expressed. Heavy prolong sedation of the women increases the risk of aspiration pneumonia and other respiratory problem requiring ventilation in Intensive Care Unit which contribute to maternal mortality and morbidity. ${ }^{25}$ Large doses of diazepam is often required and these can lead to neonatal respiratory depression, hypothermia, hypotonia and poor suckling. ${ }^{19,28}$ Retrospective study of eclampsia in Harare Maternity Hospital revealed high rate of maternal $9 \%$ and perinatal $29 \%$ mortality when diazepam was used to manage eclampsia. ${ }^{28}$ The risk of maternal and perinatal death increases as the number of fit increases and effective treatment should prevent further convulsions. The recurrence rate of convulsions of $27.9 \%{ }^{17,28}$ is considerably higher than the rate of $10 \%$ reported by Lean et al. ${ }^{29}$ This may mean that diazepam serum level may be inadequate in studies with higher recurrence rate. ${ }^{28}$ Too little diazepam results in recurrence of convulsions and too much diazepam results in over sedation and respiratory depression.

\section{PHENYT OIN}

More recently phenytoin has been advocated for eclampsia on the basis of proven efficacy for otehr types of convulsions and the lack of sedative effects. ${ }^{31,32}$ Phenytoin sodium was first used as a specific drug for prevention and control of epileptic seizure in 1938 and its pharmacological action is well described. ${ }^{33}$ Slater et al in $1987^{31}$ have reported good results with this drug in patients with severe pre-eclampsia but in cases of eclampsia the response is highly variable. The properties of this drug are rapid crossing of blood brain barrier and stabilising effect on all neuronal membranes and episodes of repetitive firing are specially supressed. ${ }^{33}$ Phenytoin enters the brain rapidly and antiwomen's weight (not practical for emergency situation) Slater et $\mathrm{al}^{31}$ recommended an initial loading dose of one gram intravenously by slow infusion in $200 \mathrm{ml}$ normal saline over 20 minutes with continuous cardiac monitoring. Maintenance dose of $500 \mathrm{mg}$ diluted in $200 \mathrm{ml}$ every 4 hour for the next 24 hour. Phenytoin serum levels were measured (Abbott TD X 1R) flourescence polarization immunoassay 30min after loading dose and every $6 \mathrm{hr}$ thereafter. The therapeutic serum level should be maintained at 40-100ug/L. The occurrence of side effects such as nausea, vomiting, nystagmus, ataxia and incoordination and arrhythmias were noted. ${ }^{34} \mathrm{~A}$ small increase in dosage can cause a disproportionately large increase in phenytoin level and rapid administration may produce cardiac arrythmias. The rate of direct intravenous injection should not exceed effective as magnesium sulphate in the control of eclamptic convulsion. The recurrent convulsion rate of $17.1 \%$ and maternal death rate $5.2 \%$ and perinatal mortality of $30.7 \%$ is reported. More 1-35 babies with phenytoin treatment have low APGAR socer at one min and admitted to special care baby unit for more than 7 days. Phenytoin appeared particularly ineffective in comparision with magnesium sulphate with the possibility even of increases in maternal ventilation, pneumonia and admission to intensive care unit so would not seem justified for the routine use in the management of eclampsia ${ }^{17}$. Similar results are reported by other studies. ${ }^{36,37}$

\section{MAGNESIUM SULPHATE}

Magnesium sulphate is the anticonvulsant agent of choice for the treatment of eclampsia in USA..$^{2530,38}$ As early as 1906 magnesium sulphate was injected intrathecally to control eclamptic seizures. ${ }^{17,37}$ Because of reports that intramuscular magnesium sulphate controlled convulsions associated with tetanus, a similar regime was used in 1926 to prevent recurrent seizures in women with eclampsia. ${ }^{39}$ In 1933 the drug was given intravenously to hundred of women with pre-eclampsia and eclampsia at the Los Angeles General Hospital. ${ }^{37}$ Later Pritchard ${ }^{32}$ and Zuspan ${ }^{40}$ advised intramuscular and intravenous treatment with magnesium sulphate. According to the National high blood pressure education working group on high blood pressure in pregnancy, most authorities in North America recommend the use of magnesium sulphate for women with pregnancy induced hypertension to prevent eclamptic seizures during labour and the immediate puerperium. ${ }^{41}$ There is little properly controlled evidence about the differential effects of anticonvulsants in eclampsia. The first two randomised trials of anticonvulsant treatment in eclampsia was published in 1990. The first trial compared magnesium sulphate with diazepam. ${ }^{28}$ Fifty one women were randomised and the results tended to favour magnesium sulphate although none of the differences were statistically significant. The second trial compared magnesium sulphate with phenytoin was stopped early when 4 of 11 women allocated phenytoin had further convulsions while none of 11 women allocated magnesium sulphate did. ${ }^{17,35}$ The collaborative eclampsia trial report was designed to estimate more reliably the differential effects of anticonvulsants commonly used for the care of women with eclampsia. This trial was a large scale study involving 1987 women in nine developing countries and provides compelling evidence in favour of magnesium sulphate rather than diazepam or phenytoin for the treatment of eclampsia. This trial has two arms: one comparing magnesium sulphate with diazepam arm and other comparing magnesium sulphate with phenytoin. There were fewer convulsions (13.2 Vs 27.9) and slightly lowering of maternal mortality (3.8 Vs 5.1) in 
women given magnesium sulphate. In the magnesium sulphate phenytoin arm: recurrent fits were $5.7 \%$ versus $17.1 \%$ and lowering of maternal mortality $(2.6 \%$ versus 6.2$)$. Other serious maternal morbidities were that fewer women allocated magnesium were ventilated $14.9 \%$ versus $22.5 \%$ fewer had pneumonia, fewer needed intensive care facilities, fewer had blood transfusion. Two women allocated magnesium sulphate had an abscess at the injection site. Non significantly more perinatal death occurred among those allocated phenytoin than those allocated magnesium sulphate compared to diazepam or phenytoin in the treatment of eclampsia in now generally

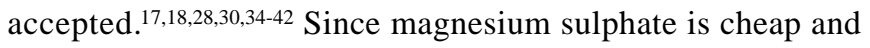
easy to produce, its ready availability should be a priority for all those concerned with maternal health and the essential drugs list of the world health organization and other bodies need to be amended accordingly. The mechanism of action of magnesium sulphate on central nervous system is unclear. It is potent vasodilator especially in cerebral vasculature and reduces intracerebral arterial spasm. ${ }^{43}$ Cortical irritability and agitation are reduced. It is suggested that magnesium sulphate acts as an anticonvulsant by means of neuronal calciumchannel blockers through excitatory amino acid receptors on the cell surface. The N-methyl-D-aspartate (NMDA) receptor is the best characterised excitatory amino acid receptor subtype. It has been shown that the anticonvulsant activity of magnesium sulphate may be partially mediated by blockage or supression of the NMDA receptor activity. ${ }^{44}$ The transient hypotensive effects may be mediated by a variety of mechanism such as increased prostacyclin release from vascular endothelium, decrease angiotensin converting enzyme activity and inhibition of catecholamines release. It also inhibit platelets aggregation. These observations fit well with the more recent recognition that pre-eclampsia is associated with widespread endothelial injury. Although the mode of action of magnesium sulphate is incompletely understood benefecial increase in renal and uterine blood flow may occur ${ }^{45}$. Despite its generalised action, magnesium sulphate does not cross the blood-brain barrier and has no effect on EEG abnormalities present with eclampsia. ${ }^{25}$ Although magnesium readily crosses the placenta and fetal magnesium level correlates well with the maternal level no untoward effects has been reported with fetus, labour process or off springs. ${ }^{46}$

\section{TREATMENT REGIME FOR MAGNESIUM SULPHATE}

There was no evidence from collaborative trial of any difference between the intramuscular and intravenous regime in their effect on recurrent convulsions. However intramuscular injections are painful and are complicated by local abscess formation in $0.5 \%$ of the cases. ${ }^{17}$ The intravenous route is therefore preferred.
INTRAVENOUS REGIME : BY ZUSPAN40

An intravenouss loading dose of $4 \mathrm{gm}$ in $20 \%$ solution over 510 minutes given slowly. This is followed by an infusion of $1 \mathrm{gm} / \mathrm{hr}$ continued for 24 hour after the last fit or delivery. The rate of infusion could be controlled manually.

\section{INTRAMUSCULAR ROUTE : PRITCHARD METHOD ${ }^{30}$}

A loading dose of $4 \mathrm{gm}$ intravenously in $20 \%$ solution over 510 mins followed by $5 \mathrm{gm}$ in $50 \%$ solution as a deep IM injection into the upper outer quadrant of each buttock. Maintenance therapy is a further $5 \mathrm{gm}$. IM every $4 \mathrm{hr}$ in alternate buttock continued for $24 \mathrm{hr}$ after the last fit.

\section{RECURRENT CONVULSION}

In both the intramuscular and intravenous regime if convulsion recurred, a further 2-4gm depending upon woman's weight $(2 \mathrm{gm}$ if $<70 \mathrm{~kg})$ is to be given intravenously over 5-10 minutes.

\section{MONITORING DURING THERAPY}

Magnesium sulphate has no sedative effect, so on recovery from the post-ictal phase, the woman should be alert or oriented. However, magnesium can depress neuromuscular transmission at the myometrial junction causing muscular paralysis as serum level increases. The therapeutic serum level needed to prevent convulsions is generally believed to be between 2-4mmol / L The clinical monitoring during magnesium therapy is as follows:
Respiratory rate
$>12 / \mathrm{min}$
Urine output
$>25 \mathrm{ml} / \mathrm{hr}$

Knee / Patellar reflexes

are present

The maintenance dose given only if above monitoring are normal. Frequent monitoring every 1 hour is necessary if complications of therapy is to be minimised. Monitoring by serum level of magnesium may not be available in many places and was not done in collaborative trial but clinical monitoring was strictly undertaken to ensure that respiration was not depressed, the knee reflex is present and the renal function is adequate. Magnesium is cleared by the kidneys so if renal function is impaired, less magnesium is required.

\section{MAGNESIUM TOXICITY}

Guidelines for the management of potential complications of magnesium sulphate.

1. Respiratory depression

Give oxygen by mask. 1 gm calcium gluconate IV slowly 
and stop magnesium therapy. Maintain the airway and nurse in recovery position.

2. Respiratory arrest

Intubate and ventilate immediately and stop magnesium sulphate therapy. Give $1 \mathrm{gm}$ calcium gluconate intravenously as $10 \%$ solution. Ventilation should be continued until the resumption of normal spontaneous respiration.

3. Absent knee reflexes

If respiration is normal, withhold further doses of magnesium sulphate until the reflexes return. If respiration is depressed manage as in no 1 above. Magnesium sulphate can be restarted if considered necessary, at a reduced rate (unless there have been further convulsions) once the reflexes have returned.

4. Urine output less than $100 \mathrm{ml}$ in 4 hour

If there are no other signs of magnesium toxicity, reduce the next magnesium dose to half the dose $(2.5 \mathrm{gm}$ IM or $0.5 \mathrm{gm} / \mathrm{hr}$ IV). When there are other signs of magnesium toxicity manage as for the appropriate section above. Review the overall management with particular attention to fluid balance and blood loss.

\section{FURTHER MANAGEMENT}

The following investigations should be done in all the women with eclampsia. Full blood count, platelets count, urea and electrolytes, serum creatinine, uric acid, fibrinogen and fibrin degradation products. Frequent pulse, blood pressure, respiratory rate and conscious level are monitored one hourly. Foley's catheter is inserted for continuous urine drainage. A central venous pressure line is inserted when appropriate. Intravenous fluid to maintain an adequate urine output.

\section{CONTROL OF HYPERTENSION}

Antihypertensive drug therapy is now routine practice in the management of women with pre-eclampsia and eclampsia. Oral therapy is started at a diastolic pressure of $100 \mathrm{~mm} \mathrm{Hg}$. Lobetelol, methyl dopa have been well studied and preferred. Hydralazine is the preferred antihypertensive drug in the management of eclampsia. In eclampsia, the blood pressure is assessed after completion of the loading dose of anticonvulsants. If the diastolic blood pressure is $115 \mathrm{~mm} \mathrm{Hg}$ dihydralazine $25 \mathrm{mg}$ in $200 \mathrm{ml}$ of normal saline is administered by controlled continuous intravenous infusion to achieve a gradual reduction of diastolic blood pressure to $100-90 \mathrm{mmHg}$. Another new antihypertensive agent Nifedipine is commonly used in pre-eclampsia, fulminating pre-eclampsia or eclampsia. In addition to greater antihypertensive action, better neonatal outcome is noted compared with hydralazine. ${ }^{47}$ It also has a beneficial effect on urinary output by increasing renal perfusion. ${ }^{48}$ There is a risk of potentiation of hypontension action and neuromuscular blockage when combined with magnesium sulphate. ${ }^{49}$

\section{OBSTETRIC MANAGEMENT}

The termination of pregnancy has classically been an important part of the management of eclampsia. In all cases the pregnancy should be terminated by induction of labour or caesarean section once the convulsions and hypertension are under control. Caesarean section is very high in eclampsia varying from $26.3 \%$ to $80.4 \%$ in different studies.50-52 It has been observed that maternal outcome was better with caesarean delivery compared to vaginal delivery in eclamptic patients. Maternal and perinatal mortality also shows favourable results $8.06 \%$ and $12.9 \%$ in caesarean delivery group whereas corresponding figures were $15.48 \%$ and $33.7 \%$ respectively in vaginal delivery ${ }^{53,54}$ Caesarean section may be beneficial to control eclampsia process as it involves complete muscle relaxation and anaesthesia. On the other hand majority of patients are in low socio-economic class, caesarean section definitely adds to morbidity because of poor patient compliance for follow-up and contraceptive use leading to the problems and complications of post caesarean pregnancy and delivery. Therefore if fits can be effectively controlled by a good anticonvulsant, it is preferrable that induction or augmentation of labour should be done with amniotomy and syntocinon infusion with the aim of vaginal delivery. However, unfavourable Bishop score is definitely an indication for caesarean section.

\section{CONCLUSION}

Eclampsia is often regarded as largely a problem for developing countries but it is still associated with a substantial mortality in the developed world. A problem for prevention and treating eclampsia is that the pathogenesis of this condition is not clearly known. The collaborative eclampsia trial now provides strong support for routine use of magnesium sulphate rather than either diazepam or phenytoin. But despite better control of convulsions than with either diazepam or phenytoin other morbidity closely related to eclampsia was not significantly influenced by magnesium sulphate. This suggests that the mechanism by which magnesium sulphate exerts its effect is largely related to the cerebral complication of eclampsia. Further studies are needed to assess the usefulness of treatment to prevent eclampsia in women with pre-eclampsia comparing routine use of anticonvulsant with none. 


\section{REFERENCE}

1 Leitch Gr. Caneron AD val ker JJ. The changing pattern of ed anpsi a over a 60 yeer peri od Br. J. Obstet Gynecd 1997: 104: $917-22$

2 Dougl as KA Rednan CVG ECl anpsi a in the uni ted $\mathrm{K}$ ngdom BM 1994: 309: 1395- 1400

3 Vorl d Heal th Ogari zati on I nternati onal Col I aborati ve Study of hypertensi ve di sorder of pregnancy. Ceographic vari ti i on in the i nci dence of hypertensi on in pregnancy. AMJ Costet Gynecol 1988: 158: 80-83

4 Whit tefield CR Dewhurst's textbook of obstetrics and gyneecol ogy for Post gradutes $5^{\text {th }}$ Ed ti on B acknel I Sci ence CTed. 1995: 81, 83, 90, 92, 177, 182, 186, 187, 209

5 D cknan W. The toxaenia of pregnancy. St. Li ons C V. Masby $2^{\text {nd }}$ ed ti on 1952: 17: 507-17

6 Departnent of hed th wel sh office, scotti sh hone and hed th depart nent. DHSS Nbrthern I rel and, Report on Conf i dence i nqu ri es into naternal death in the uri ted ki ngdom1988- 1990 London HMSO 1994.

7. Dougl as KA Rednan CVG ECl anpsi a in the uni ted ki ngdom The BEST vay forvard. Br J Obstet Gynecol. 1992: 99: 35559

8 Dul ey L Maternal nortal i ty associ ated with hypertensi on di sorder of pregnancy in Africa, Asi a, Lati in Aneri ca ad Cari bean. B. J. Costet. Gynecd 1992 99. 547-53

9 Faril y Hal th Dvi si on Mri stry of $\longmapsto a l$ th 1996. Naki ng safe notherhood work in Nepal: Programati c and el enents of chal I enges. J NA 1996: 34: 118: 180-84

10. Ecl anpsi a worki ng group ecl anpsi a in Bangl adesh: a revi ew and gi del i ne. Band adesh J Costet G/necol. 1996: 12: 1-25

11. Sawney H Aggarva N Bi suas R Vasi sti ta K Copal an S. Maternal Mortal ity associ ated with ed anpsi a and severe pre ed anpsi a of pregnancy. Jr. Costet. Gynecd. Peseerch 2000. 26: 5: $351-56$

12. Arora P, Gangul y RP, Suai ns, Qunachi gui A PayramP, Determinarts of neternal nortal ity in ed arpsi a in I nda Aust. N J. Obstet. Gynecol 1994; 34:537-539

13. Agudl o AC, Katary-gota $A C$ Case contrd study of risk factors for conpl i cated ecl anpsi a. Obstet. Gynecol. 1997; 90. 17275

14. Suzin $S$, Qha $\mathrm{NN}$ Prakash $A$ Baha $B D$ Naternal and perinatal nortal i ty die to ed anpsi a. I nd a Paed atri c J r. 1993; 30(6): 771- 73

15. Ozynbi a BC, I be AL, Ecl anosi a in Enugu Eastern $\mathrm{N}$ geri a Acta: Costet Gynecol Scand 1993; 72(3): 189-92

16. Dougl as KA Rednan C/G ECl anpsi a in the uni ted ki ngdom The BEST vay forvard Br. J. Costet. Gynecd. 1992; 99. 35559
17. Diey L Carrdi G Bdizan J et. al. What ati conmi sarts for uonen with ecl anpsi a-evi dence fromthe col I aborati ve ecl anpsi a tri al . Lancet 1995; 345: 1455-63

18. A - Mul hi mS, At Naj ash, Rehnan J, Pehna N\$. Managenent of Ed arpsia a revei wof 50 coses. Jr. of Costet. Grecd. 1994 14: $40-49$

19. Wi ghnan $\mathrm{H} H$ bbard $\mathrm{B} n$, Posen $\mathrm{M}$ Peri natal nortal ity and norbi di ty associ ati on with ecl anpsi a. BM 1978; 2: 235-37

20. Chauchary $\mathrm{P}, \mathrm{ECl}$ anpsi a in materni ty hospi tal : i npact of chang ing in the interverti on strategy. Saweri $r 6^{\text {h }}$ Neti ond conf erence of NESOG

21 Acharya G Schd tz S. Ecl anpsia in Patan Hospital: A two year retrospecti ve study. J MA, 1991; 29: 254 58

22. Trel our SA Cooper DN Bremecke SP, GrehamMM Martin NG An Australian study of the genetic basis of pre ed anosia and ecl anpsi a. Anh Obstet. Gynecol. 2001; 184: 374-81

23. Arngri nason $\mathrm{R}$ B ornsson $\mathrm{S}$, Ceir rsson $\mathrm{A}$, B ornsson $\mathrm{H}$ Val ker JJ, Saneda G Contic and faril i al pred spositi on to ecl arpsi a and preed anosi a in a defi ned popl atio on B. J. Costet. Greed. 1990; 97: 762-69

24. Pedhan C, Ecl anpsi a Still K KII s. BMI 1988; 296: 1209-1210

25. Nood ey J. Treatnent of Ecl anpsi a. B. J. Costet. Gynecd. 1990; 97: 99-101

26. Hitton JD, J anes DK, Sti rrat GM Dougl as KA Redhan CVG Managenent of severe pre ecl anpsi a and ecl anpsi a by $U$ K consul tants. B J. Costet. Gynecd. 1992; 99. 53456

27. Redman CW Roberts J M Managenent of pre ecl anpsi a. Lancet 1993; 341: 1451-59

28. Crovther $C$ Magnesi umversus di azepami $n$ the nanagenent of ecl anpsi a, a randorised contrd l ed tri al. B. J. Costet. Gynecol . 1990; 97: 110-117

29. Lean $\mathrm{TH}$ RatnumSS, Si vasanbo $R$ Lse of Berzod azepi nes in the managenent of ecl anpsi a. J. Costet. Gynecol. B. Comon W1968; 75: 856- 62

30. Pri tchard J A Curni nghamFG Pritchard SA The parkl and nenorial hospital protocal for treatnent of eclanpsia. Eval uati on of 245 cases. AmJ. Obstet. Gynecol. 1984; 148: 951- 60

31. Sl ater RM WII nax H Srith VDet. al. Phenytai $n$ i ifusi on in severe pre-ecl anpsi a. Lancet 1987; 1: 1417-21

32. Coyag KT, Qiv SR Sing e high dose of intravenous phenytain sod umfor the treatnert of ed anpsi a. Acta Costet. Gynecd. Scand 1990; 69: 115-18

33. GI man AG Goodman LS, Ral I TW Mrad E (eds) 1985. Goodman and G I man's the Phar nacol ogi cal basi s of Therapeuti cs, $7^{\text {th }}$ ed. NAc Mll an NewYork.

34. Appl eten MP, Kuchl T, Racbel et. al. Mgnesi umSu phate versus Phenytai $n$ for Sei zure prophyl axi s in Pregnancy i nduced hypertensi on. Am J. Costet. Gynecol. 1991; 165: 907-13 
35. Donminsse J. Phenyt oi $n$ Sod umand nagnesi umsul phate in the nanagenent of ecl anpsi a. Br. J. Costet. Gynecd. 1990, 97: $104-9$

36. Pobson SC, Pedforn N Sevi ar J et. al. Phenytoi n Prophyl axis in severe preed anosi a and ed anpsi a. B. J. Costet. Gynecd. 1793; 100: 623: 8

37. Lueas J M Leveno KT, Cunni nghamGA A conpari si on of nagnesi umsul phate with phenytoi $n$ for the prevention of ecl anpsi a. N Eng. J. Næd. 1995; 333: 201-15

38. Si bai $B M, N A$ Cudbi $\mathrm{J} H$ Anderson $\Phi$ L L Lshitz J, Dtts PV. Ecl anpsi a observati on for 67 recent cases. Costet. Gynecd 1981; 58: 608- 13

39. Pritchard JA The use of Mgnesi umi on in the managenent of ed anarogeri c toxaerna. Surg. gynecol. obstet. 1955; 100. 131- 140

40. Zuspan FP. Treatnent of severe pre ecl anpsi a and ecl anpsi a Uin. Obst. Gynecol. 1996; 9.95472

41. Nati and high blood pressure educati on programverk ing grap report on high dl ood pressure in pregnancy. Am J. Costet. Gynecol. 1990; 163: 1689-712

42 Bal la A Dak G, Dhal I K A safer and nore effecti ve trectnart reg ne for ed arpsia. Aust. N马 dbst. gynecd. 1994; 34: 14448

43. Nonesi umsu phate revi ew of d i i cal pharnacd ogy apd i ed to dostetri cs. B. J. dbstet. gynecd. 1998; 105: 260-68

44. Cotton DB, Hal I akh, J anusz C, I rtenkan LSN Bornan RF, Central anti convul sant ef fect of nagnesi umsul phate on $\mathrm{N}$ nethy -Daspartate i nduced sei zures. Am J. Costet. Gynecd. 1993; 168: $974-78$

45. Nel son SH Suresh NE Nonesi umsu phate i nduces rel axati on of uteri ne arteri es frompregnancy and non-pregnart pati ents. Am J. Obstet. Gynecol. 1991; 164: 1345-50

46. Leveno $\mathrm{J}$, A exander J M M I nti re DD, Lucas $M$. Does nagnesi umsul phate gi ven for prevertion of ed anpsi a af fect the outcone of I abour. Am J. Costet. Gynecol. 1998; 178: 707- 12

47. J anes A Scardo MD Vernil I i on St, Hogg BB, Newnan RB, Hanodynanic in pre-ecl anpti c hypertensi ve energenci es. Am J. Costet. Gynecd . 1996; 175: 336-46

48. J don PB, Hitt $\mathrm{CK}$ C Cononer VB The use of $\mathrm{N}$ fed pi ne dring the postpartumperi od in pati ent with severe pre ecl anpsi a. Am J. Costet. Gynecd. 1990; 162: 788-92

49. Anin MB, GI ad $y$, Shal ev $E$. The conbi nati on of nagnesi um su phate and ri fed pi ne: a cause of Neuronoscul ar bl ockage B. J. Costet. Gynecol. 1994; 101: 263-63

50. Kuruvill a A BassawB, Si ngh RS. A retrospecti ve study of ed anosi a in the tri ri dal. Jr. Costet. Gnecd. 1992; 12 169172

51. Veraval I a N, Ganande S, I ngl e KM A Fi ve year anal ysi s of ecl anpsi a. J. Cost. Gynecd. I nd a 1989, 39. 512-515

52. Mingogl ee JA Matri vate SN ECl anpsi a at Ga Runkuma Hbspi tal. Sauth Afri can Ned cal J arnal. 1996; 86(12): 1536 9

53. Bhattacharya PK, Purkayast ha S, Basu M Nandal R Caesarean Secti on in Ed anosi a: Still a di lema anal ysi s of 314 cases. J r. Obstet. Gynecol. I ndi a 1992; 42(1): 51-5

54. Arora R Suai $\mathrm{S}$, Agraval A Habeebul I an S. I npact of node of del i very on maternal nortal i ty in ecl anpsi a. J I nd a NAd Assoc. 1997; 95(4): 103-6

$$
\text { estes es es }
$$

\title{
3d Bemial SouthAsian Card ac Conference of SAARC Gardi ac Sod ety
}

F®b. 27-29, 2004

\author{
Soaltee Crowne Plaza Hotel \\ Tahachal, Kathmandu, Nepal
}

\section{Cardiac Society of Nepal}

P.O. Box: 11360, Budhanilkantha Marg 781, Kathmandu, Nepal,

Email: info@cardiology.org.np

Tel: 977-1-4371322 Ext.123, Fax: 977-1-4371123

Website: www.cardiology.org.np 